04

\title{
TRANSFORMATIONS FOR THE SUSTAINABLE DEVELOPMENT GOALS
}

\author{
Mahmood Yekeh Yazdandoost \\ Advisor Expert, Biodiversity \& Wildlife Bureau, \\ Natural Environment \& Biodiversity Division, Department of Environment, Tehran, Iran \\ Email: yazdandoost3000@gmail.com
}

\begin{abstract}
The Sustainable Development Goals (SDGs) address the most pressing social-economic and environmental challenges currently facing the globe. This paper identifies crucial issues to overcome the challenges through holistic approach by restructuring the existing socio-economic elements of society to enhance transformation towards sustainability. The assessment shows holistic approach transform socio-economic environment to the ideal of sustainability.
\end{abstract}

Key words: Sustainable Development Goals, Global Policy, Holistic Approach, Transformation.

\section{Introduction}

Brundtland report with considering the importance of sustainability for future success, expressing: "human has got the capacity to make development sustainable for the present and the future generations" (UN, 1987). Based on that statement, UN inserted at Agenda 21, the definition of sustainable development as a process that have to consider socio-economic and environmental issues as one fully, inseparable and integrated components, which will require broader range of public participation (UN, 1992). Therefore the main goal and output of sustainable development is the link between health, economy, society and environment. Currently humanity is facing multiple global challenges. To mention a few: pollution, deforestation, biodiversity loss, global warming and climate change, deprivation, inequality, pandemic diseases and social exclusion. Each of these issues would impact biological metabolism of the planet, hence ecological and social well-being. Since also they are intricately linked to each other, would amplify the related risks. The humanitarian and social crises are to a large extent due to unequal access to energy and materials and opportunities to satisfy needs and wants. Dealing successfully with these challenges requires holistic transformations.

The holistic approach implies fundamental changes at all levels of social, economic, political, and cultural structures, which means a fundamental reorganizing of present society. The holistic approach of sustainability stands for the integrity of the environment and all its life support systems. The holistic transformations enhance technological innovation and system shifts to improve organizational performance and social coherence. Most countries in the world are facing reduction in biological capability, i.e., more than the replenishment of their natural resources they harvest resources in their territories. Sustainable development is possible only if the limits of nature's capacity for regeneration are respected. To achieve ecological sustainability, respect for the limits of nature and a responsibility of all human beings should become a moral obligation (International Union, 1989). 
The contribution of biological resources and ecosystem connectivity to human development is well known (MEA, 2005). Reduction in biological capability is not only collapses ecological system, but also creates problem with population health and creativity. The needy and illconditioned population usually affect more by environmental agitation, as they are more dependent on services received by environment. In spite of the fact, that biodiversity creates community health and wealth, biodiversity is getting lost at an unparalleled pace. Nearly all countries show decline in biodiversity. It is happening as a result of immense anthropogenic activities (Barnosky et al., 2011; Hanski et al., 2012). Such large-scale transformations reduce ecosystem services, creating problem to human health and well-being (Cardinale et al., 2012). At the same time, although agricultural sector generates outcomes with respective impacts to rural zones, supply-chains, economy, society and environment representing a key piece for achieving sustainable development to each country and to the planet, landscape conversion for the farming purposes impact biodiversity and global climate stability.

Improvements in watershed management contribute to ecosystem stability and climatechange mitigation and adaptation. Considering the irreversible nature of biodiversity loss and global warming the risks of delaying towards sustainable development is noticeable. The ecosystem goods and services that make a direct relief to human health and welfare are already degraded in many parts of the world. The impacts of climate change affect large areas in Iran and other parts of the world and can undermine economic growth and human development. Many of the impacts of climate change can occur beyond its original location to create conflicts and competition for resources (Stern, 2007). The vision of Smart and Connected Communities (SCC) promote link and solidarity in society. The sustainability in society depends on economic and environmental health, social equity, and participation in planning and implementation. The challenge is to find the right policy for appropriate transformation.

\section{Methodology}

For the holistic mission, a comprehensive national policy in needed for successful transition to human welfare, ecosystem connectivity and environmental stability. The harmful policies which degrade the environment and humanity as a whole should be corrected by subsidizing green and friendly program of action. Combining societal engagement, with economic instrument and law enforcement may pave the road towards sustainability. Education and awareness plays important role in this process.

\section{Results and Discussion}

Sustainable development is a governance issue and the rule of law should act as an empowering tool to engage public-private-people participation (4p) to take right actions. Since the 3 dimensions of sustainable development make the situation complex, an integrated and multifaceted policy should work for environmental sustainability. To create a planetary sustainable society it is necessary that organizations and people of countries adopt sustainable attitudes. Private and public organizations are responsible for implementing policies, plans, projects and activities and generate products and services. The result indicates that, in order to be efficient, Sustainable Development Goals (SDGs) should be adopted by a broader range of connected social groups and be implemented by broader cross-sectoral policies. However, the following issues need special considerations:

- Energy shift towards renewable energy;

- Green production by green technology; 
- Political commitment towards innovation and creativity;

- Use of indigenous knowledge for natural landscape sustainability; and,

- Reduction of ecological footprint for wildlife conservation and natural forest production.

The design of National Sustainable Development Mechanism (NSDM) is crucial to the overall engagement of stakeholders in achieving the implementing programs.

\section{Recommendations}

1. Create good governance with participatory, transparent and accountable decision-making;

2. Integrate sustainable development into national policies and strategies;

3. Engage all relevant stakeholders into decision-making;

4. Develop mechanism for inter-sectoral cooperation, capacity building and awareness raising;

5. Adopt a strategy for the sustainable consumption and production;

6. Ensure political will for the three pillars of sustainable development;

7. Strengthen national institutional facilitation technology for sustainable development;

8. Provide mechanism for the transfer of technology;

9. Incorporate sustainability issues into government planning and decision-making;

10. Develop financing mechanism into cross-sectoral policy;

11. Strengthen national monitoring, evaluation and reporting capacity for sustainable development;

12. Establish advisory board to all the targets of sustainable development.

\section{Conclusion}

Sustainable development is about human prosperity, economic growth and environmental stability. The social cohesiveness is critical to the success of sustainable development. The present global approach is not supportive to the long-term sustainability, as environment including biological resources getting more degraded day by day. Shortcoming of Governments policies, private sectors collaboration and civil society's engagement all contribute to the weak institutional capacities for enhancing sustainable development. Transformational approach towards sustainability needs massive transition for change. Legal framework with broader cross-sectoral scope would provide protection services to green investments and innovation. Legislation in place would mandate implementation process. The role of advisory board is to advise institutions to take effective actions on the management of sustainable development goals. In this regard, an accountability framework in reinforcement of sustainable development programs should be built with an admission of responsibility.

\section{Acknowledgement}

All scientific literatures released by UN and other agencies including Department of Environment that have been used in this research article are highly appreciated.

\section{References}

1. Barnosky et al. (2011). Nature. 471:51-57.

2. Cardinale et al. (2012). Nature. 489:326.

3. International Union for the Conservation of Nature (1989). San Jose, Costa Rica: International Union, in conjunction with the U.N. Environmental Program and the World Wildlife Foundation.

4. MEA (2005). The Report of Millennium Ecosystem Assessment.

5. Hanski et al. (2012). Proceedings of the National Academy of Science, USA.

6. Stern, N. (2007). The Economics of Climate Change.

7. United Nations (1987). Our Common Future Report.

8. United Nations (1992). Agenda 21, Item 8.3 - Sustainable Development. 